\title{
Heart rate variability in hypoxic ischemic encephalopathy: correlation with EEG grade and 2-y neurodevelopmental outcome
}

\author{
Robert M. Goulding 1,2, Nathan J. Stevenson ${ }^{1,2}$, Deirdre M. Murray ${ }^{1,2}$, Vicki Livingstone ${ }^{1,2}$, Peter M. Filan ${ }^{1,3}$ and \\ Geraldine B. Boylan ${ }^{1,2}$
}

BACKGROUND: The study aims to describe heart rate variability (HRV) in neonatal hypoxic ischemic encephalopathy (HIE) and correlate HRV with electroencephalographic (EEG) grade of HIE and neurodevelopmental outcome.

METHODS: Multichannel EEG and electrocardiography (ECG) were assessed at 12-48 h after birth in healthy and encephalopathic full-term neonates. EEGs were graded (normal, mild, moderate, and severe). Neurodevelopmental outcome was assessed at 2 y of age. Seven HRV features were calculated using normalized-RR (NN) interval. The correlation of these features with EEG grade and outcome were measured using Spearman's correlation coefficient.

RESULTS: HRV was significantly associated with HIE severity $(P<0.05)$ : standard deviation of NN interval (SDNN) $(r=-0.62)$, triangular interpolation of $\mathrm{NN}$ interval histogram (TINN) $(r=-0.65)$, mean NN interval $(r=-0.48)$, and the very low frequency (VLF) $(r=-0.60)$, low frequency (LF) $(r=-0.67)$ and high frequency (HF) components of the NN interval $(r=-0.60)$. SDNN at 24 and $48 \mathrm{~h}$ were significantly associated $(P<0.05)$ with neurodevelopmental outcome $(r=-0.41$ and -0.54 , respectively).

CONCLUSION: HRV is associated with EEG grade of HIE and neurodevelopmental outcome. HRV has potential as a prognostic tool to complement EEG.

$\mathbf{H}$ ypoxic ischemic encephalopathy (HIE) occurs in 1-6 per 1,000 live full-term births (1). In more severe HIE, there is an increased risk of death or neurodisability (2-4). Neonates with HIE are admitted into a neonatal intensive care unit (NICU) where it is important to monitor brain function in order to support management and intervention, and aid prognostic decision making. Continuous, multichannel electroencephalography (EEG), is the gold standard for assessing brain function in neonates with HIE (5). EEG monitoring is a standard of care for the management, monitoring, and prognosis of neonates with HIE, but is rarely available immediately after birth or on an out-of-hours basis. Most tertiary units do have access to amplitude-integrated EEG (aEEG) but because formal training in aEEG methodologies is rarely available misinterpretation of the aEEG can occur (6). This suggests the need for other markers that can accurately grade the severity of HIE and which can easily be obtained in the early postnatal period to support clinical decision making.

The electrocardiogram (ECG) is routinely recorded in neonates with HIE and methods of estimating the magnitude of the variation in time between successive heartbeats (the normalized-RR interval or $\mathrm{NN}$ interval) provides a measure of heart rate variability (HRV). HRV provides noninvasive assessment of both the parasympathetic and sympathetic control of heart rate (HR) $(7,8)$. Evidence of alterations in heart rate following hypoxia has long been observed in animal research (9) and adult human studies have also documented altered HRV following traumatic brain injury (10). The ability of HRV to grade HIE severity in neonates has also been explored in a small number of studies, and has been shown to change in encephalopathic neonates $(11,12)$; however, the relationship with neurological outcome is unknown.

Our aim was to analyze EEG and ECG data from a defined group of healthy and encephalopathic neonates, to calculate HRV features and assess their ability to grade the severity of injury by comparing them to EEG grade, and predict longterm neurodevelopmental outcome.

\section{RESULTS}

In total, 61 neonates were included in the assessment of simultaneous ECG and EEG recordings at $12-48 \mathrm{~h}$ after birth (17 healthy neonates, 44 neonates with HIE: 22 with an initial mild EEG grade, 9 with an initial moderate EEG grade, and 13 with an initial severe EEG grade). An example EEG and the NN interval for all grades of HIE are shown in Figure 1 and additional clinical details are shown in Table 1. Neonates were recorded prior to the introduction of therapeutic hypothermia (TH).

Of these 61 neonates, 36 had simultaneous ECG and EEG recordings at $12 \mathrm{~h}$ ( 6 healthy neonates, 16 mild EEG grade, 


\section{Articles $\mid$ Gouldingetal.}

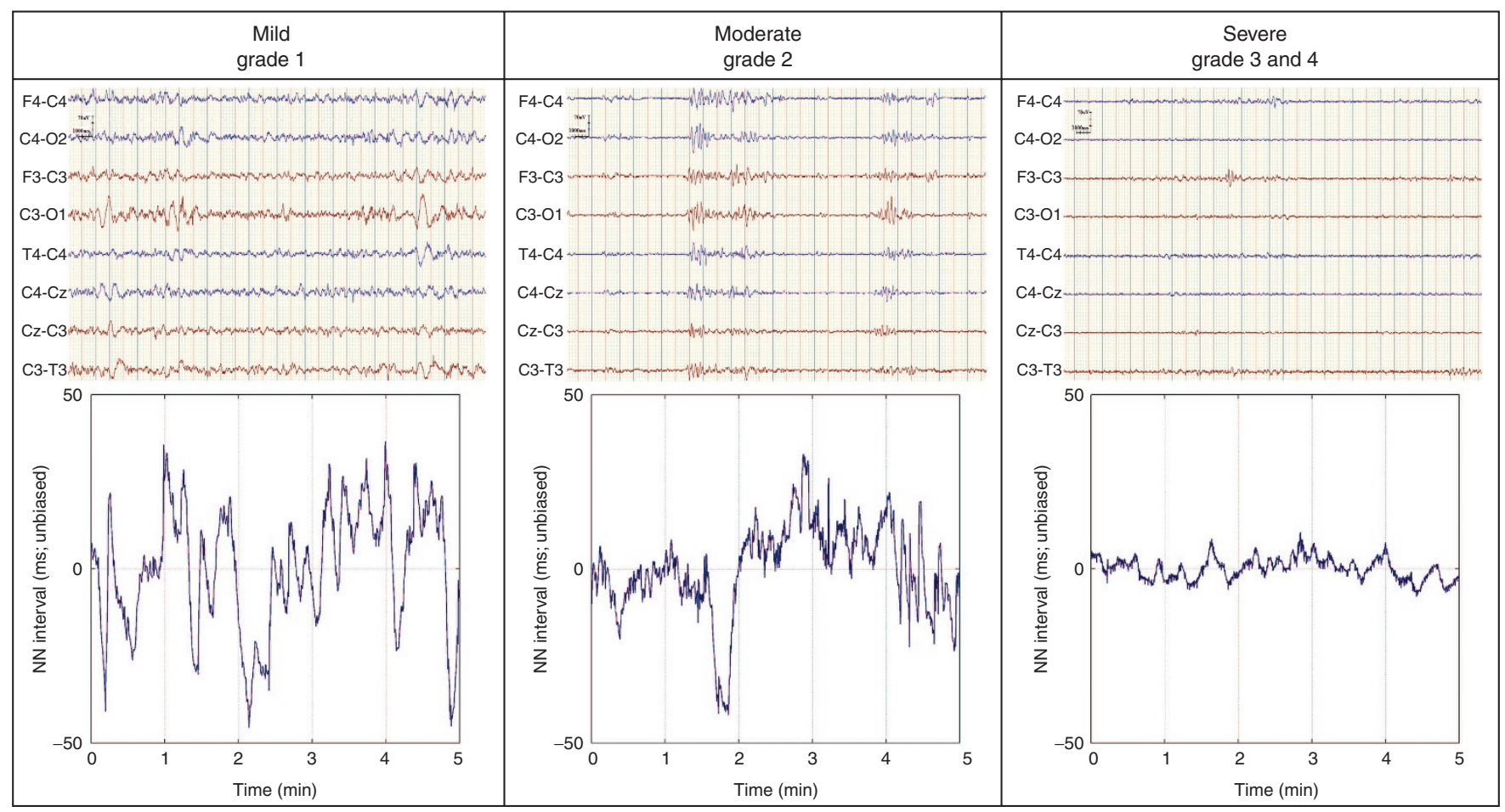

Figure 1. Examples of varying degrees of EEG severity and corresponding heart rate variability. Five minute segments of NN interval and $30 \mathrm{~s}$ segments of EEG are shown. NN interval plotted minus Mean NN. SDNN values for HR plots include mild: $17.6 \mathrm{~ms}$, moderate: $12.8 \mathrm{~ms}$, and severe: $3.1 \mathrm{~ms}$.

Table 1. Clinical demographics for healthy neonates and neonates with HIE

\begin{tabular}{lcc}
\hline Demographics & $\begin{array}{c}\text { HIE group } \\
(n=44)\end{array}$ & $\begin{array}{c}\text { Healthy group } \\
(n=17)\end{array}$ \\
\hline Gestational age $\left(\right.$ weeks) $^{\mathrm{a}}$ & $39(36,42)$ & $40(38,41)$ \\
${\text { Birth weight }(\mathrm{g})^{\mathrm{a}}}$ & $3,384(1,830,5,040)$ & $3,601(2,980,4,060)$ \\
$\mathrm{pH}^{\mathrm{a}}$ & $6.81(6.5,7.24)$ & - \\
Lactate $^{\mathrm{a}}$ & $11.75(4.2,21)$ & - \\
${\text { Base excess }(\mathrm{mEq} / \mathrm{l})^{\mathrm{a}}}_{\text {Gender }(\mathrm{M} / \mathrm{F})^{\mathrm{b}}}$ & $-14.21(-25,-4.2)$ & - \\
Neonates with EEG seizures & $26 / 18$ & $11 / 6$ \\
Drug therapy & 14 & 0 \\
$\quad$ AEDs & & 0 \\
Morphine & 13 & 0
\end{tabular}

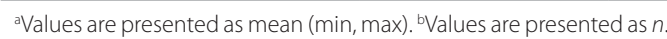

5 moderate EEG grade, 9 severe EEG grade), 38 recordings at $24 \mathrm{~h}$ (11 healthy neonates, 17 mild EEG grade, 6 moderate EEG grade, 4 severe EEG grade), and 16 recordings at $48 \mathrm{~h}$ ( 7 mild EEG grade, 5 moderate EEG grade, 4 severe EEG grade). Thus, a total of 90 simultaneous EEG and ECG recording time-points were included in the analysis.

A statistically significant and negative correlation was found between HRV features and EEG grade $(P<0.05)$, indicating that as EEG grade worsens, HRV decreases (Table 2). The standard deviation of the NN interval (SDNN) for all groups is shown in Figure 2.
Table 2. The correlation between HRV features and EEG grade of encephalopathy measured at 12-48 h after birth (normal EEG grade, mild EEG grade, moderate EEG grade, and severe EEG grade)

\begin{tabular}{lc}
\hline Feature & $r^{\mathrm{a}}(n=67)$ \\
\hline SDNN $(\mathrm{ms})^{\mathrm{b}}$ & $-0.62(-0.75$ to -0.45$)$ \\
TINN $(\mathrm{ms})^{\mathrm{b}}$ & $-0.65(-0.77$ to -0.49$)$ \\
Mean VLF $\left(\mathrm{ms}^{2}\right)^{\mathrm{b}}$ & $-0.60(-0.74$ to -0.43$)$ \\
Mean LF $\left(\mathrm{ms}^{2}\right)^{\mathrm{b}}$ & $-0.67(-0.78$ to -0.51$)$ \\
Mean HF $\left(\mathrm{ms}^{2}\right)^{\mathrm{b}}$ & $-0.60(-0.73$ to -0.42$)$ \\
LF-HF ratio & $0.06(-0.19$ to 0.29$)$ \\
Mean NN $(\mathrm{ms})^{\mathrm{b}}$ & $-0.48(-0.65$ to -0.27$)$ \\
\hline aSpearman's rank correlation coefficient, values are presented as $r(95 \% \mathrm{Cl}) .{ }^{\mathrm{b}} \mathrm{P}<0.05$, \\
significantly different from 0.
\end{tabular}

When comparing normal and HIE groups a significant difference was found: measured HRV features were reduced in neonates with HIE (Table 3). Significant reductions were found for SDNN, triangular interpolation of $\mathrm{NN}$ interval histogram (TINN), very low frequency component of the NN interval (VLF), low frequency component of the NN interval (LF), high frequency component of the $\mathrm{NN}$ interval (HF) $(P<0.001$ for all), and mean NN interval (Mean NN) $(P=0.002)$. The low frequency/high frequency $(\mathrm{LF} / \mathrm{HF})$ ratio was not significantly different between healthy and encephalopathic neonates.

Analysis within the HIE group identified all HRV features, except LF/HF ratio, to be significantly different between mild and severe EEG grades. All HRV features showed significant differences between mild and moderate EEG grades (Table 4). 


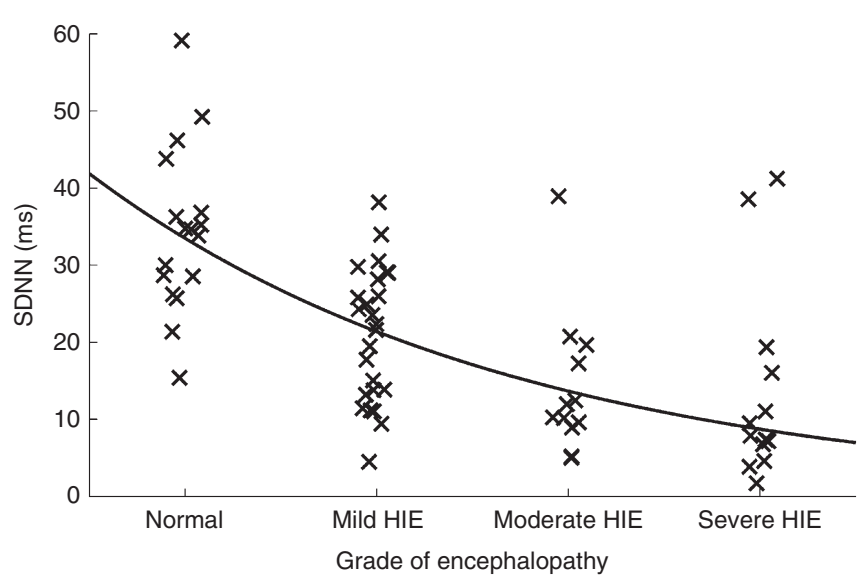

Figure 2. The SDNN grouped according to the degree of encephalopathy (normal, mild HIE, moderate HIE, severe HIE) $(n=67)$. An exponential function was fit to the data using a robust fit (Bisquare weighting). Random jitter was added for display purposes.

Table 3. The difference in HRV features between healthy neonates and neonates with HIE measured at 12-48 h after birth

\begin{tabular}{|c|c|c|c|}
\hline \multirow[b]{3}{*}{ Feature } & \multicolumn{2}{|c|}{ Group } & \multirow[b]{3}{*}{$P$ value } \\
\hline & $\operatorname{HIE}(n=73)$ & Healthy $(n=17)$ & \\
\hline & \multicolumn{2}{|c|}{ Geometric mean $(95 \% \mathrm{Cl})$} & \\
\hline SDNN (ms) & $14.84(12.10-18.20)$ & $32.88(27.87-38.80)$ & $<0.001^{*}$ \\
\hline TINN (ms) & $48.34(39.41-57.27)$ & $106.38(93.50-119.27)$ & $<0.001^{*}$ \\
\hline $\begin{array}{l}\text { Mean VLF } \\
\left(m s^{2}\right)\end{array}$ & 96.15 (63.01-146.71) & $422.10(297.83-598.21)$ & $<0.001^{*}$ \\
\hline $\begin{array}{l}\text { Mean LF } \\
\left(m s^{2}\right)\end{array}$ & $53.16(33.91-83.33)$ & $375.65(263.47-535.61)$ & $<0.001^{*}$ \\
\hline $\begin{array}{l}\text { Mean HF } \\
\left(\mathrm{ms}^{2}\right)\end{array}$ & $11.25(6.77-18.72)$ & $93.64(61.74-142.00)$ & $<0.001^{*}$ \\
\hline LF-HF ratio & $5.87(4.78-7.20)$ & $4.41(3.27-5.94)$ & 0.108 \\
\hline $\begin{array}{l}\text { Mean-NN } \\
(\mathrm{ms})\end{array}$ & $477.98(459.46-497.25)$ & $516.85(501.92-532.22)$ & $0.002^{*}$ \\
\hline
\end{tabular}

aTINN was not log transformed. ${ }^{*} P<0.05$ : Statistically significant result.

\section{Drug Administration}

Within our HIE group $(n=44), 19$ did not receive any sedation or antiepileptic drugs. The remaining 25 neonates $(7$ mild, 8 moderate, and 10 severe HIE; based on initial EEG grade) received various combinations and doses of morphine, phenobarbitone, phenytoin, and clonazepam (Table 1). Within the mild group ( $n=7)$ : one neonate received $\geq 1$ antiepileptic drug (AED) and no morphine, three neonates received morphine only, and three neonates received morphine and $\geq 1$ AED. Within the moderate group $(n=8)$ : six neonates received $\geq 1$ AED and no morphine, and two neonates received morphine only. Within the severe group $(n=10)$ : six neonates received $\geq 1 \mathrm{AED}$, one neonate received morphine only, and three neonates received morphine and $\geq 1$ AED. It was not possible to perform an investigation into the potential confounding effects of all medications used but we were able to analyze the effects of morphine and phenobarbitone when comparing all EEG grades of HIE. Statistically significant differences remained for all HRV features when adjusting for morphine. When adjusting for phenobarbitone all HRV features remained significantly different, except TINN and LF features.

\section{Prediction of Neurodevelopmental Outcome}

Neurodevelopmental outcome was available for all neonates with HIE $(n=44)$. Of these, 20/44 had an abnormal outcome: 6 deaths, 6 with cerebral palsy, 6 with global developmental delay, 1 with significant gross motor delay, and 1 with isolated speech delay. The ability of EEG grade and HRV to predict neurodevelopmental outcome at $2 \mathrm{y}$ of age is summarized in Table 5. EEG grade was shown to correlate significantly with outcome at each time-point $(12,24$, and $48 \mathrm{~h}$ ) with the highest predictive value for both normal and abnormal outcome seen at $12 \mathrm{~h}$. HRV features were most predictive of a normal outcome at $24 \mathrm{~h}$ (SDNN, TINN, VLF, $\mathrm{LF}$ ) and most predictive of an abnormal outcome at $48 \mathrm{~h}$ (SDNN, VLF, HF).

Table 4. The difference in HRV features between neonates with a mild EEG grade, moderate EEG grade, and severe EEG grade measured at 12-48 h after birth

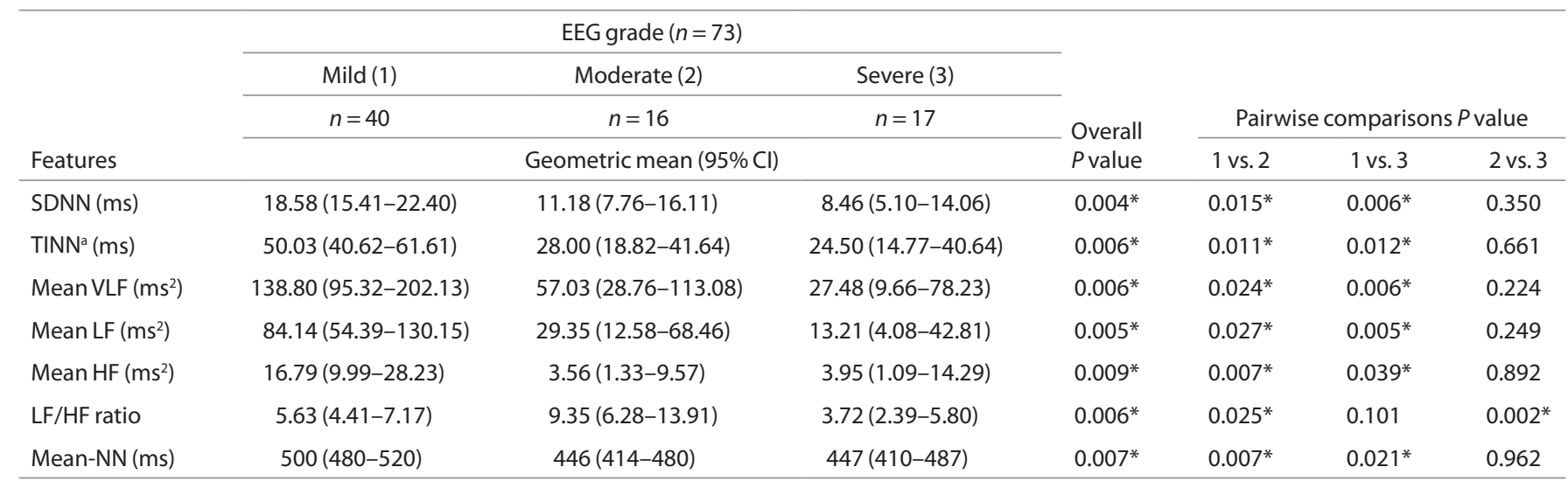

Mild group epochs: 16 at $12 \mathrm{~h}, 17$ at $24 \mathrm{~h}$ and 7 at $48 \mathrm{~h}$; moderate group epochs: 5 at $12 \mathrm{~h}, 6$ at $24 \mathrm{~h}$ and 5 at $48 \mathrm{~h}$; severe group epochs: 9 at $12 \mathrm{~h}, 4$ at $24 \mathrm{~h}$ and 4 at $48 \mathrm{~h}$ after birth.

aTINN was not log transformed. ${ }^{*} P<0.05$ : Statistically significant result. 
Table 5. The correlation between HRV/EEG and neurodevelopmental outcome for neonates with HIE, taken at each time-point (12, 24, and 48h after birth)

\begin{tabular}{|c|c|c|c|c|c|c|c|}
\hline Feature & $n$ & $\begin{array}{l}\text { Time-point } \\
\text { (hours } \\
\text { after birth) }\end{array}$ & $r^{\mathrm{a}, \mathrm{b}}$ & $A U C^{b}$ & NPV $(\%)^{b}$ & PPV $(\%)^{\mathrm{b}}$ & Threshold \\
\hline EEG grade & 30 & 12 & 0.84 (0.62 to 0.97$)$ & $0.95(0.85-1.00)$ & $100.0(100.0-100.0)$ & $78.6(52.9-100.0)$ & Mild \\
\hline EEG grade & 27 & 24 & 0.45 (0.05 to 0.77$)$ & $0.73(0.53-0.93)$ & $76.5(56.5-95.0)$ & $60.0(30.0-90.0)$ & Mild \\
\hline SDNN & 27 & 24 & $-0.41(-0.71$ to -0.07$)$ & $0.74(0.54-0.93)$ & $90.0(69.2-100.0)$ & $52.9(26.7-75.0)$ & $21 \mathrm{~ms}$ \\
\hline TINN & 27 & 24 & $-0.40(-0.73$ to -0.10$)$ & $0.76(0.56-0.94)$ & $83.3(58.3-100.0)$ & $53.3(25.0-76.9)$ & $56 \mathrm{~ms}$ \\
\hline VLF & 27 & 24 & $-0.49(-0.73$ to -0.09$)$ & $0.74(0.55-0.94)$ & $84.6(66.7-100.0)$ & $57.1(29.4-83.3)$ & $129 \mathrm{~ms}^{2}$ \\
\hline LF & 27 & 24 & $-0.48(-0.74$ to -0.13$)$ & $0.79(0.57-0.94)$ & $90.9(71.4-100.0)$ & $56.3(30.8-80.0)$ & $106 \mathrm{~ms}^{2}$ \\
\hline EEG grade & 16 & 48 & 0.52 (0.13 to 0.85$)$ & $0.80(0.58-0.96)$ & $57.1(20.0-100.0)$ & $88.9(62.5-100.0)$ & Mild \\
\hline SDNN & 16 & 48 & $-0.45(-0.87$ to -0.14$)$ & $0.79(0.60-1.00)$ & $62.5(33.3-100.0)$ & $100.0(100.0-100.0)$ & $14 \mathrm{~ms}$ \\
\hline VLF & 16 & 48 & $-0.48(-0.87$ to -0.18$)$ & $0.80(0.62-1.00)$ & $62.5(33.3-100.0)$ & $100.0(100.0-100.0)$ & $61 \mathrm{~ms}^{2}$ \\
\hline $\mathrm{HF}$ & 16 & 48 & $-0.42(-0.85$ to -0.08$)$ & $0.73(0.51-0.98)$ & $41.7(18.2-75.0)$ & $100.0(100.0-100.0)$ & $3 m s^{2}$ \\
\hline
\end{tabular}

\section{DISCUSSION}

To our knowledge, this is the first time a range of HRV features have been described in a large group of healthy and encephalopathic full-term neonates, as graded by EEG, between 12 and $48 \mathrm{~h}$ after birth. We have also correlated HRV features with long-term neurodevelopmental outcome in a group of encephalopathic neonates.

We have shown that HRV is negatively associated with EEG grade of HIE severity and demonstrated significant differences in HRV between mild and moderate EEG grades and also between mild and severe grades. This is an important finding as it is sometimes difficult to distinguish between mild and moderate grades of encephalopathy using currently available clinical markers (13). Neonates with severe HIE, on the other hand, are generally easier to identify clinically. A bedside tool that could provide a more objective measure of HIE severity would be valuable, particularly if it helped distinguish between mild and moderate grades. We have shown that HRV is a useful tool for the prediction of long-term neurodevelopmental outcome and this could be useful for NICUs without access to EEG monitoring, especially when decisions regarding management and intervention are required.

\section{Healthy vs. HIE}

When comparing our healthy and encephalopathic neonates we found a reduction in HRV features in encephalopathic neonates: SDNN (Figure 2), TINN, VLF, LF, HF, and mean NN. Within the subcortical structures of the brain, the brainstem contributes to HRV control (14), and brainstem injury will result in reduced HR control and contractility (15). Subcortical neuronal injury has been shown to reduce the variability of NN interval in preterm fetal sheep exposed to asphyxia (16) and involvement of the brainstem in neonates exposed to acute near-total asphyxia has also been documented (17). Subcortical neuronal loss may explain some of the HRV changes seen within our HIE group. Reduced vagal tone in moderate and severe HIE has been described previously $(11,18)$. It is generally accepted that the HF feature is mediated by the parasympathetic system (19) and the LF feature represents sympathetic activity, although this association is less clear (20). HF and LF features were reduced in our HIE group, implying a reduction in overall autonomic function in HIE. Physiological factors affecting the NN interval have been investigated in human and animal populations. In an adult study, the LF feature reflected baroreceptor reflex modulation (21) and in a study of anesthesia in a rat population, it was found that respiration, manifesting as respiratory sinus arrhythmia (RSA), reflects parasympathetic control, and consequently, the HF feature (22). HIE can cause alterations in respiratory control and dysregulation of blood pressure control (15) which, in turn, will have an impact on the LF and HF features.

HRV has also been investigated in neonates with sepsis, with a reduction in autonomic function documented (23). Similar inflammatory mechanisms are present in neonates with HIE and may also contribute to reduced $\operatorname{HRV}(24,25)$.

\section{HIE Severity}

HRV features highlighted significant differences between EEG grades of encephalopathy. Comparison of mild EEG grade with moderate and severe EEG grades showed significant reductions for all features, with the exception of LF/HF ratio which was significantly increased between mild and moderate EEG grades, and then significantly reduced between moderate and severe EEG grades. This was due to the more pronounced relative drop in the HF feature between mild and moderate EEG grade. Importantly, a reduction in LF and HF features was seen across all EEG grades reflecting a reduction in overall autonomic control as EEG grade worsened. This reduction 
was significant between both mild and moderate, and mild and severe groups.

Our HRV analysis is comparable to the small number of studies that are available in a similar study population. Aliefendioglu et al., assessed healthy and encephalopathic term neonates $(n=46)$ and observed a reduction in LF and HF normalized units of HRV between their control group (73.1 \pm 6.9 and $20.3 \pm 5.57)$, moderate group (57.8 \pm 9.4 and $30.6 \pm 7.0$ ), and severe group $(27.8 \pm 13.0$ and $48.9 \pm 7.1)$; however, EEG was not used to grade the severity of HIE (11). In a study by Vergales et al., neonates receiving TH for HIE $(n=67)$ underwent HRV and EEG monitoring. EEG recordings were graded as normal, mild, moderate, or severe before being categorized into two groups: normal/mild and moderate/severe. Depressed HRV was observed in neonates with moderate/severe EEG grades ( $P=0.02$; SD of RR intervals $17.6 \pm 9.7 \mathrm{~ms}$ ) when compared with neonates who had a normal/mild EEG grade (SD of RR intervals $26.8 \pm 11.4 \mathrm{~ms}$ ) (12).

\section{Neurodevelopmental Outcome}

In pediatric and adult studies, the sustained reduction of $\mathrm{HRV}$ has been correlated with the severity of illness, outcome and mortality rate (26-29). When assessing outcome in neonates, Vergales et al. found that neonates who died had lower SDNN compared to survivors $(10 \pm 5.1 \mathrm{~ms}$ vs. $24.3 \pm 9.5 \mathrm{~ms}, P<0.001)$ (12). These studies have demonstrated HRV as a potential predictor of outcome. In our study, features of NN interval (SDNN, TINN, VLF, LF, and HF) have been shown to have predictive values for neurodevelopmental outcome at $2 \mathrm{y}$ of age (Table 5). Furthermore, neonates who have an abnormal outcome, have a SDNN that remains low at $48 \mathrm{~h}$ after birth, whereas, neonates with normal outcome have higher SDNN values (Figure 3) and these results reaffirm the findings of Vergales et al. (12). HRV features were not significantly correlated with outcome at $12 \mathrm{~h}$ after birth but were correlated at
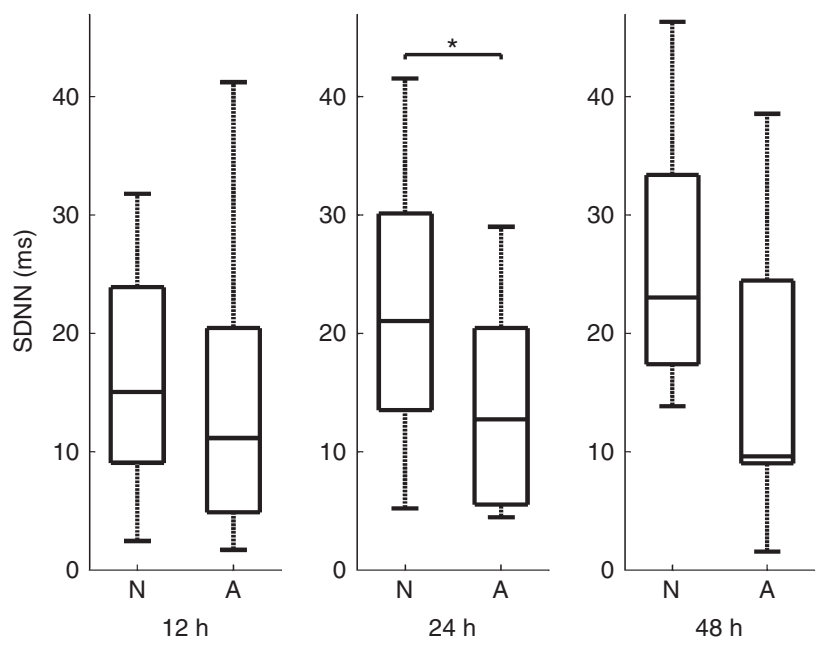

Figure 3. Boxplot of SDNN recorded at 12,24 , and $48 \mathrm{~h}$ after birth in neonates with normal (N) and abnormal (A) 2-y outcome. SDNN measured at $12 \mathrm{~h}$ ( $N=19$ neonates, $A=11$ neonates), $24 \mathrm{~h}(N=17$ neonates, $A=10$ neonates) and $48 \mathrm{~h}$ ( $N=5$ neonates, $A=11$ neonates) after birth. A $P$ value less than 0.05 is denoted by *.
24 and $48 \mathrm{~h}$; the predictive value for abnormal outcome using HRV features increased with age of measurement. This was in contrast to the EEG which was better able to predict a normal outcome at an earlier age of measurement ( $12 \mathrm{~h}$ after birth).

Overall, EEG has high predictive value for normal 2-y outcome when recorded at $12 \mathrm{~h}$ after birth and this reduces as the measurement time increases from the primary injury. EEG has greatest predictive value for abnormal outcome when measured at $48 \mathrm{~h}$ after birth. HRV features were predictive of normal and abnormal outcome between 24 and $48 \mathrm{~h}$ after birth.

When assessing the relationship between HRV features and EEG grade, a negative correlation was apparent. The magnitude of the correlation suggests that EEG and HRV, if measured together, could provide complementary information and enhance the prediction of outcome in neonates with HIE.

\section{Limitations}

This study has a number of limitations because of its retrospective nature. The primary aim of the original study was to assess EEG activity and, as such, optimum ECG quality was not always achieved. A larger prospective HRV study in the context of HIE, which includes mild, moderate, and severe EEG grades, would overcome such limitations. Any prospective HRV recruitment should ensure ECG quality is optimal for the duration of monitoring and, if possible, include early timepoints $(<6 \mathrm{~h}$ after birth) as this is when decisions regarding neuroprotective therapies are considered. This study has used EEG and ECG recorded at a time prior to the implementation of $\mathrm{TH}$; however, the study does provide valuable reference data that will allow the effects of TH on HRV after hypoxic ischemic injury to be studied.

There are also several possible confounders such as: stress, pain, medication, and ventilation. All these factors are present in neonates with HIE and while they have been shown to affect HR $(11,23)$, an effect on HRV does not necessarily follow (12). When adjusting for the effects of morphine in our study, all features of HRV remained significantly different between EEG grades of HIE. When adjusting for Phenobarbitone, TINN and LF showed no significant difference between EEG grades of HIE and all other HRV features remained significant.

\section{Conclusion}

We have shown a significant association between HRV and EEG grade of HIE severity in full-term neonates. We have also shown a significant association between HRV and neurodevelopmental outcome at $2 \mathrm{y}$ of age.

These results demonstrate the potential of HRV features as a physiological marker of HIE severity in full-term neonates and as a useful predictor of long-term neurodevelopmental outcome.

\section{METHODS}

This retrospective, observational, study was conducted in the NICU of two maternity hospitals in Cork with a total of 8,000 deliveries per year. The study period was September 2003 to July 2007. Data was collected prior to the introduction of TH. Term neonates $(>37 \mathrm{wk}$ of gestation) with HIE were recruited if they fulfilled $\geq 2$ of the following 
criteria: initial arterial $\mathrm{pH}<7.1$, Apgar score $\leq 6$ at $5 \mathrm{~min}$ of life, initial capillary or arterial lactate level of $>7 \mathrm{mmol} / \mathrm{l}$, or abnormal neurological examination or clinical seizures. A group of healthy full-term neonates with uneventful deliveries and normal newborn examination (Amiel Tison Neurological Examination) were recruited from the postnatal wards over the same study period.

Ethical approval was obtained from the Clinical Research Ethics Committee of the Cork Teaching Hospitals. The parents of all eligible neonates were approached and written informed consent was obtained.

Silver-chloride EEG electrodes were applied to the neonatal scalp for all EEG recordings and followed the international 10-20 system of electrode placement, as modified for neonates. The number of recording electrodes applied differed between our control group and HIE group; neonates within the control group had active electrodes applied at F3, F4, Cz, T3, T4, P3, P4 (30); neonates with HIE had electrodes applied at F3, F4, C3, C4, T3, T4, O1, O2, Cz. A reference and ground electrode were applied for both groups and ECG electrodes were applied to both shoulders. A NicoletOne EEG monitor (Carefusion, Madison, WI) was used to record continuous video-EEG and ECG for at least $48 \mathrm{~h}$ in HIE neonates and for $1-2 \mathrm{~h}$ in the control group. The EEG and ECG signals were sampled at $256 \mathrm{~Hz}$.

For this study, only those neonates with good quality simultaneous ECG and EEG data were included. We aimed to extract 1-h recordings at three time-points $(12,24$, and $48 \mathrm{~h})$. This was not always possible due to varying quality of recordings and as a result there were neonates with only one or two time-points included. This meant that each neonate had between one and three time-points included and we have accounted for this in our statistical analysis. Time-points containing electrographic seizure activity were excluded.

\section{EEG Analysis}

All neonates had EEG recordings graded as normal, HIE 1; mildly abnormal, HIE 2; moderately abnormal, HIE 3; severely abnormal, or HIE 4; inactive, according to the grading scheme described by Murray et al. (5). EEGs were graded by two clinical physiologists (RMG, GBB) and any inter-rater differences were discussed and a consensus achieved. EEGs were graded at each time-point (12, 24, and 48h) before being categorized as either healthy (normal EEG and AmielTison assessment), mildly, moderately, or severely (severe or inactive EEG) abnormal. An important point to note in the EEG analysis was that the EEG grade for a neonate could change as the encephalopathy evolved. For example, a neonate may have a moderately abnormal EEG at $12 \mathrm{~h}$ which could improve to mildly abnormal at 24 or $48 \mathrm{~h}$. The EEG would be included in the moderately abnormal category at $12 \mathrm{~h}$ but is then included in the mildly abnormal category at 24 or $48 \mathrm{~h}$. HRV was then analyzed in relation to the grade of EEG at each of the three time points $(12,24$, and $48 \mathrm{~h})$.

\section{ECG Analyses}

The R-peaks of the ECG waveforms in each 1-h recording were automatically identified using the Pan-Tompkins method (31). The time of each R-peak was adjusted using quadratic interpolation. Incorrectly identified R-peaks were corrected, based on visual inspection (RG). Artefact is an on-going issue for any neonatal recording and periods of clear movement artefact were discarded systematically (32). Following these steps, we regarded the adjusted and corrected $\mathrm{RR}$ interval as normalized RR interval (NN interval). We then calculated the following seven time- and frequency-domain HRV features: mean NN interval (Mean NN), standard deviation of the NN interval (SDNN), triangular interpolation of NN interval histogram (TINN), the power in high frequency (HF), low frequency (LF), very low frequency bands (VLF) of the NN interval and low frequency/high frequency $(\mathrm{LF} / \mathrm{HF})$ ratio $(8,33)$. SDNN and TINN are the primary time-domain features of overall HRV (8). VLF, LF, and HF measure specific aspects of HRV within different frequency bands.

Each ECG file was segmented into 5-min epochs and the seven HRV features were estimated from the NN intervals within each epoch. The mean of the HRV features across all available epochs recorded from each neonate was used in the statistical analysis. All HRV features were estimated from an interpolated $\mathrm{NN}$ interval time series. The interpolation was performed using Hermite splines and the sampling frequency was $256 \mathrm{~Hz}$. The frequency-domain representation of the interpolated NN interval was estimated using a Periodogram (8). The following frequency bands, specific to neonates, were applied:

(i) VLF: 0.01-0.04 Hz;

(ii) LF: $0.04-0.2 \mathrm{~Hz}$; and

(iii) HF: $0.2-2 \mathrm{~Hz}$.

The frequency bands applied for the frequency-domain features were consistent with previous studies in neonates (34).

\section{Neurodevelopmental Outcome}

All neonates with HIE had their neurodevelopmental outcome assessed at 2 y of age using the revised Griffiths mental development scales. Abnormal outcome was defined as death, cerebral palsy, or a Griffith's Quotient (GQ) of <87 (5). We assessed the ability of HRV features at 12,24 , and $48 \mathrm{~h}$ after birth to predict neurodevelopmental outcome at $2 \mathrm{y}$ of age. We also compared our findings with the predictive value of simultaneously recorded EEG grade.

\section{Statistical Analyses}

Measures of association were calculated between HRV and EEG grade for all groups (healthy, mild HIE, moderate HIE, and severe HIE). For each HRV feature we used an average value for each baby across their observations when their EEG grade remained the same (e.g., If a baby had a mild EEG grade at two time-points, the average of the HRV values at those time-points was calculated). For six neonates, where their EEG grade changed, we kept both sets of observations in the analysis.

For the comparison between healthy and HIE neonates, for each HRV feature, all available time-points $(12,24$, and $48 \mathrm{~h}$ after birth) were included in the analysis. Observations from the same neonate across different time-points were averaged, giving one summary value per feature for each neonate. For each HRV feature, differences between healthy and encephalopathic neonates were investigated, using the independent samples $t$-test.

For comparison between EEG grades of HIE (mild, moderate, and severe), for each HRV feature, individual data from all time-points were included. To account for repeated measures, a linear mixed model with a random intercept was used. To control for the potential confounding effect of medication use, adjusted analyses were performed, with medication use included as a fixed effect in the linear mixed model. For all statistical models, the variances were allowed to differ across groups, if it improved model fit.

All statistical analyses were performed in SAS 9.3 (SAS Institute, Cary, NC) or Stata 13.0 (StataCorp LP, College Station, TX). All features (except TINN for comparison between healthy and encephalopathic neonates) were log transformed prior to data analysis. All tests were twosided and a $P$ value $<0.05$ was considered to be statistically significant.

The ability of EEG and HRV features to predict 2-y neurodevelopmental outcome was estimated using several performance metrics (coded in a Matlab environment): Spearman's correlation coefficient, area under the receiver operator characteristic (AUC), positive predictive value (PPV; where an abnormal test result predicts an abnormal outcome) and negative predictive value (NPV; normal test result predicts a normal outcome). Confidence intervals were estimated using a bootstrap with 1,000 resampling iterations.

\section{ACKNOWLEDGMENTS}

The authors acknowledge the assistance of Denis Dwyer, UCC software engineer, in developing the HRV software, the assistance of Irina Korotchikova, Research Fellow, in collecting and recording data in healthy neonates, and staff from the NICU of Cork University Maternity Hospital for their assistance and support throughout the recruitment period.

\section{STATEMENT OF FINANCIAL SUPPORT}

This research was supported by a Science Foundation Ireland Principal Investigator Award (SFI 10/IN.1/B3036), a Science Foundation Ireland Centres Programme (12/RC/2272), and a Wellcome Trust Strategic Translational Award (098983).

Disclosure: There is no conflict of interest to disclose. 


\section{REFERENCES}

1. Shankaran S. Neonatal encephalopathy: treatment with hypothermia. J Neurotrauma 2009;26:437-43.

2. Kurinczuk JJ, White-Koning M, Badawi N. Epidemiology of neonatal encephalopathy and hypoxic-ischaemic encephalopathy. Early Hum Dev 2010;86:329-38.

3. Graham EM, Ruis KA, Hartman AL, Northington FJ, Fox HE. A systematic review of the role of intrapartum hypoxia-ischemia in the causation of neonatal encephalopathy. Am J Obstet Gynecol 2008;199:587-95.

4. Vannucci RC, Vannucci SJ. Perinatal hypoxic-ischemic brain damage: evolution of an animal model. Dev Neurosci 2005;27:81-6.

5. Murray DM, Boylan GB, Ryan CA, Connolly S. Early EEG findings in hypoxic-ischemic encephalopathy predict outcomes at 2 years. Pediatrics 2009;124:e459-67.

6. Boylan G, Burgoyne L, Moore C, O’Flaherty B, Rennie J. An international survey of EEG use in the neonatal intensive care unit. Acta Paediatr 2010;99:1150-5.

7. Mourot L, Bouhaddi M, Perrey S, Rouillon JD, Regnard J. Quantitative Poincaré plot analysis of heart rate variability: effect of endurance training. Eur J Appl Physiol 2004;91:79-87.

8. Malik M. Heart rate variability: standards of measurement, physiological interpretation, and clinical use. Circulation 1996;93:1043-65.

9. Wibbens B, Westgate JA, Bennet L, et al. Profound hypotension and associated electrocardiographic changes during prolonged cord occlusion in the near term fetal sheep. Am J Obstet Gynecol 2005;193(3 Pt 1):803-10.

10. Lowensohn RI, Weiss M, Hon EH. Heart-rate variability in brain-damaged adults. Lancet 1977;1:626-8.

11. Aliefendioğlu D, Doğru T, Albayrak M, DibekMısırlığlu E, Şanlı C. Heart rate variability in neonates with hypoxic ischemic encephalopathy. Indian J Pediatr 2012;79:1468-72.

12. Vergales BD, Zanelli SA, Matsumoto JA et al. Depressed heart rate variability is associated with abnormal EEG, MRI, and death in neonates with hypoxic ischemic encephalopathy. Am J Perinatol 2013;31:855-62.

13. DuPont TL, Chalak LF, Morriss MC, Burchfield PJ, Christie L, Sánchez PJ. Short-term outcomes of newborns with perinatal acidemia who are not eligible for systemic hypothermia therapy. J Pediatr 2013;162:35-41.

14. Novak V, Novak P, deMarchie M, Schondorf R. The effect of severe brainstem injury on heart rate and blood pressure oscillations. Clin Auton Res 1995;5:24-30.

15. Volpe JJ. Neurology of the Newborn. 3rd edn. Philadelphia: WB Saunders, 1995.

16. George S, Gunn AJ, Westgate JA, Brabyn C, Guan J, Bennet L. Fetal heart rate variability and brain stem injury after asphyxia in preterm fetal sheep. Am J Physiol Regul Integr Comp Physiol 2004;287:R925-33.

17. de Vries LS, Groenendaal F. Patterns of neonatal hypoxic-ischaemic brain injury. Neuroradiology 2010;52:555-66.

18. Biswas AK, Scott WA, Sommerauer JF, Luckett PM. Heart rate variability after acute traumatic brain injury in children. Crit Care Med 2000;28: 3907-12.

19. Pomeranz B, Macaulay RJ, Caudill MA, et al. Assessment of autonomic function in humans by heart rate spectral analysis. Am J Physiol 1985;248 (1 Pt 2):H151-3.

20. Malliani A, Pagani M, Lombardi F, Cerutti S. Cardiovascular neural regulation explored in the frequency domain. Circulation 1991;84:482-92.
21. Rahman F, Pechnik S, Gross D, Sewell L, Goldstein DS. Low frequency power of heart rate variability reflects baroreflex function, not cardiac sympathetic innervation. Clin Auton Res 2011;21:133-41.

22. Moldovan M, Spulber S, Saravan V, Iosifescu R, Zagrean AM, Zagrean L. The relationship between respiratory sinus arrhythmia and heart rate during anesthesia in rat. Rom J Physiol 2004;41:31-9.

23. Fairchild KD, O'Shea TM. Heart rate characteristics: physiomarkers for detection of late-onset neonatal sepsis. Clin Perinatol 2010;37:581-98.

24. Walsh BH, Boylan GB, Livingstone V, Kenny LC, Dempsey EM, Murray $\mathrm{DM}$. Cord blood proteins and multichannel-electroencephalography in hypoxic-ischemic encephalopathy. Pediatr Crit Care Med 2013;14:621-30.

25. Chiesa C, Pellegrini G, Panero A, et al. Umbilical cord interleukin-6 levels are elevated in term neonates with perinatal asphyxia. Eur J Clin Invest 2003;33:352-8.

26. Dekker JM, Schouten EG, Klootwijk P, Pool J, Swenne CA, Kromhout D. Heart rate variability from short electrocardiographic recordings predicts mortality from all causes in middle-aged and elderly men. The Zutphen Study. Am J Epidemiol 1997;145:899-908.

27. Goldstein B, Fiser DH, Kelly MM, Mickelsen D, Ruttimann U, Pollack MM. Decomplexification in critical illness and injury: relationship between heart rate variability, severity of illness, and outcome. Crit Care Med 1998;26:352-7.

28. Papaioannou V, Giannakou M, Maglaveras N, Sofianos E, Giala M. Investigation of heart rate and blood pressure variability, baroreflex sensitivity, and approximate entropy in acute brain injury patients. J Crit Care 2008;23:380-6.

29. Haji-Michael PG, Vincent JL, Degaute JP, van de Borne P. Power spectral analysis of cardiovascular variability in critically ill neurosurgical patients. Crit Care Med 2000;28:2578-83.

30. Korotchikova I, Connolly S, Ryan CA, et al. EEG in the healthy term newborn within 12 hours of birth. Clin Neurophysiol 2009;120:1046-53.

31. Pan P, Tompkins WJ. A real-time QRS detection algorithm. IEEE Trans Biomed Eng 1985;32:230-6.

32. Longin E, Schaible T, Lenz T, König S. Short term heart rate variability in healthy neonates: normative data and physiological observations. Early Hum Dev 2005;81:663-71.

33. Chon K, Scully CG, Lu S. Approximate entropy for all signals. IEEE Eng Med Biol Mag 2009;28:18-23.

34. Doyle OM, Korotchikova I, Lightbody G, Marnane W, Kerins D, Boylan GB. Heart rate variability during sleep in healthy term newborns in the early postnatal period. Physiol Meas 2009;30:847-60.

(1) () $\ominus$ This work is licensed under a Creative Commons Attribution-NonCommercial-NoDerivs $\quad 4.0$ International License. The images or other third party material in this article are included in the article's Creative Commons license, unless indicated otherwise in the credit line; if the material is not included under the Creative Commons license, users will need to obtain permission from the license holder to reproduce the material. To view a copy of this license, visit http://creativecommons.org/licenses/ by-nc-nd/4.0/ 